\title{
Plant Cation-Chloride Cotransporters (CCC): Evolutionary Origins and Functional Insights
}

\author{
Sam W. Henderson ${ }^{+}\left(\mathbb{D}\right.$, Stefanie Wege ${ }^{(1)}$ and Matthew Gilliham * \\ ARC Centre of Excellence in Plant Energy Biology, School of Agriculture, Food and Wine, \\ University of Adelaide, PMB1, Glen Osmond, SA 5064, Australia; sam.henderson@adelaide.edu.au (S.W.H.); \\ stefanie.wege@adelaide.edu.au (S.W.) \\ * Correspondence: matthew.gilliham@adelaide.edu.au; Tel.: +61-8-8313-8145 \\ + Present address: CSIRO Agriculture and Food, Waite Campus, Locked Bag 2 Glen Osmond, \\ South Australia 5064, Australia.
}

Received: 30 November 2017; Accepted: 1 February 2018; Published: 6 February 2018

\begin{abstract}
Genomes of unicellular and multicellular green algae, mosses, grasses and dicots harbor genes encoding cation-chloride cotransporters (CCC). CCC proteins from the plant kingdom have been comparatively less well investigated than their animal counterparts, but proteins from both plants and animals have been shown to mediate ion fluxes, and are involved in regulation of osmotic processes. In this review, we show that CCC proteins from plants form two distinct phylogenetic clades (CCC1 and CCC2). Some lycophytes and bryophytes possess members from each clade, most land plants only have members of the CCC1 clade, and green algae possess only the CCC2 clade. It is currently unknown whether $\mathrm{CCC} 1$ and $\mathrm{CCC} 2$ proteins have similar or distinct functions, however they are both more closely related to animal KCC proteins compared to NKCCs. Existing heterologous expression systems that have been used to functionally characterize plant CCC proteins, namely yeast and Xenopus laevis oocytes, have limitations that are discussed. Studies from plants exposed to chemical inhibitors of animal CCC protein function are reviewed for their potential to discern CCC function in planta. Thus far, mutations in plant CCC genes have been evaluated only in two species of angiosperms, and such mutations cause a diverse array of phenotypes-seemingly more than could simply be explained by localized disruption of ion transport alone. We evaluate the putative roles of plant CCC proteins and suggest areas for future investigation.
\end{abstract}

Keywords: KCC; NKCC; plant membrane transport; plant nutrition; anion; Golgi; plasma membrane; AT1G30450; Arabidopsis

\section{Introduction}

Cation chloride $\left(\mathrm{Cl}^{-}\right)$cotransporters (CCC) are membrane-integral solute carriers that mediate electroneutral translocation of $\mathrm{Cl}^{-}$, coupled to potassium $\left(\mathrm{K}^{+}\right)$and/or sodium $\left(\mathrm{Na}^{+}\right)$. Belonging to the Solute Carrier 12 (SLC12) family of proteins, CCC members are present in plants, animals, fungi and prokaryotes [1]. It has been previously shown that the SLC12 family consists of up to four subfamilies including NKCC/NCC, KCC, CCC9 and CCC interacting protein (CIP9) [1]. Phylogenetic analyses have revealed that all plant CCC proteins belong to the KCC subfamily of CCCs [1-3]. In mammals, mutations in CCC proteins can cause diseases such as Gitelman syndrome, affecting kidney function [4], and neurological disorders [5]. To date, plant CCC transporters have been cloned and functionally characterized from Arabidopsis (Arabidopsis thaliana) [3], rice (Oryza sativa) [6] and grapevine (Vitis vinifera) [7]. Disruption of genes that encode CCC proteins in plants leads to severe growth and developmental phenotypes [3,6]. However, compared to CCC proteins from animals, CCC proteins from plants have been studied in much less detail. Therefore, many questions regarding plant CCC function remain unanswered. For example, can the phenotypes of plant $c c c$ mutants be explained 
simply by disrupted ion transport? Are there other in planta functions of plant CCC proteins that are yet to be revealed? This review describes what is currently known about CCC proteins in plants, investigates their evolutionary origins and phylogenetic relationships, evaluates the current methods used for characterizing plant CCC proteins, and describes avenues for future investigations to broaden our understanding of this unique class of plant transporter.

\section{Evolution of Plant CCCs}

Cation-chloride cotransporters have been identified in all kingdoms including prokaryotes and eukaryotes [1]. However, the diversity of CCCs within the plant kingdom has not been thoroughly examined. Table 1 summarizes CCC genes identified in a selection of plants with sequenced genomes. Putative orthologues of Arabidopsis AtCCC1 (At1G30450) were obtained from Ensembl Plants [8], and polyploid species were excluded. The genome of the basal angiosperm Amborella trichopoda encodes a single CCC gene, and the number of CCC genes per genome of eudicots is generally one or two. Selected diploid monocots with sequenced genomes have two or three CCC genes per genome. To date, chlorophyte (green algae) genomes appear to contain either none or a single gene. It is unknown whether these numbers will remain consistent as well-annotated genome sequences of more species are revealed, but an absence of CCC genes from selected chlorophytes would demonstrate that CCC genes are not crucial for the survival of some single-celled species. Worden et al. [9] compared the genomes of two species of the genus Micromonas, marine algae, with two other marine algal species of the genus Ostreococcus. In that study, the genomes of the Micromonas spp. were shown to contain a single CCC gene each, whereas the Ostreococcus spp. lacked a CCC in their genomes [9]. Like Ostreococcus spp., the model organism and freshwater algae Chlamydomonas reinhardtii lacks a CCC in its genome (Table 1). The observation that land plants possess CCC genes, and only some green algae contain CCCs while others do not, suggests that CCC genes were present in the last common ancestor of green algae (chlorophytes) and land plants (streptophytes) [10]. Unlike chlorophytes, all investigated streptophytes contain at least one CCC in their genome (Table 1). Surprisingly, the genome of the bryophyte and model organism Physcomitrella patens encodes seven CCC genes (Table 1).

Using the predicted protein sequences encoded by the CCC genes identified in Table 1, we prepared a phylogenetic tree (Figure 1). The phylogenetic analysis revealed that plant CCC proteins form two distinct clades, that we have denoted CCC1 and CCC2. These two distinct phylogenetic branches have previously been identified in the moss P. patens, and both clades were shown to be phylogenetically related to the KCC subfamily [2]. We identified the CCC2 clade to be present only in lycophytes, bryophytes and algae (Figure 1). P. patens contains members from both families, leading to the large number of CCC genes in the P. patens genome. The CCC 2 family is not present in vascular plants beyond the lycophyte lineage, while the investigated chlorophytes do not harbor members of the CCC1 clade, and angiosperms contain exclusively CCC 1 family members (Figure 1). Thus evolutionarily, it appears that gene duplication events have occurred at the base of the streptophytes, leading to the formation of two distinct clades, with some species having many paralogs (e.g., P. patens). Later in evolution, it is likely that gene-loss events have occurred, leading to an absence of $C C C 2$ genes in angiosperms. Fewer copies of $C C C 1$ genes in eudicots compared to monocots, could result from gene loss in eudicots, or a second duplication event in monocots. Such events could arise in plants during DNA replication and recombination, unequal crossing over during meiosis, transposable elements that allow for transduplication or retropositioning, or the accumulation of mutations leading to non-functionalization [11,12]. Whole genome duplication and polyploidization in plants would lead to even greater copies of CCC genes. Addressing such questions will become practicable with the continued sequencing and annotation of complex genomes from additional plant species such as Triticum aestivum (wheat) [13] and Chenopodium quinoa (quinoa) [14]. The observation that SmCCC1.1 and SmCCC1.2 from Selaginella moellendorffii only differ by a single amino acid residue strongly suggests that gene duplication is the reason for multiple CCC1 copies in that species. Gene duplication could also be the cause of multiple CCC genes in some other vascular 
plant species, which raises the possibility of redundancy and a release from selective pressure on one or more of the CCC paralogs. It is noteworthy that rice, which contains two CCC paralogs in the genome (OsCCC1.1 and OsCCC1.2), displayed a reduced growth phenotype when only OsCCC1.1 was mutated, and OsCCC1.2 remained intact [6]. It is possible that some CCC genes, in plants with multiple CCC paralogs, are non-functional but this remains to be tested.

Comparing the functional properties of proteins from the CCC1 and CCC2 clades would be interesting to determine whether subfunctionalization or neofunctionalization occurred within the plant CCC gene family. There are regions of interest within primary structures of CCC proteins that could be used to probe for functional differences between CCC1 and CCC 2 clades, and these are shown in Figure 2. Compared to proteins of the CCC2 family, the CCC1 proteins have a shorter amino (N)-terminus, and an insertion (with low percent identity) towards the carboxyl (C)-terminus (Figure 2, residues 1050 to 1350). Plant CCC proteins are long polypeptides of approximately 700 to 1200 amino acids in length (Figure 2), and have been predicted to possess large hydrophilic C-termini $[3,7]$. How these features affect the structure, function, and regulation of CCC proteins is unknown.

Table 1. Distribution of CCCs among selected Viridiplantae species with sequenced, annotated genomes.

\begin{tabular}{|c|c|c|}
\hline Common Name & Species & $C C C$ per Genome \\
\hline \multicolumn{3}{|c|}{ Chlorophytes } \\
\hline Green algae (freshwater) & Chlamydomonas reinhardtii & 0 \\
\hline Green algae (marine) & Ostreococcus lucimarinus & 0 \\
\hline Green algae (marine) & Ostreococcus tauri & 0 \\
\hline Green algae (marine) & Micromonas pusilla & 1 \\
\hline Green algae (marine) & Micromonas sp. RCC299 & 1 \\
\hline \multicolumn{3}{|c|}{ Bryophytes } \\
\hline Spreading earthmoss & Physcomitrella patens & 7 \\
\hline Liverwort & Marchantia polymorpha & 2 \\
\hline \multicolumn{3}{|c|}{ Tracheophytes } \\
\hline Selaginella & Selaginella moellendorffii & 4 \\
\hline Amborella & Amborella trichopoda & 1 \\
\hline \multicolumn{3}{|c|}{ Monocots } \\
\hline Brachypodium & Brachypodium distachyon & 3 \\
\hline Rice & Oryza sativa & 2 \\
\hline Sorghum & Sorghum bicolor & 2 \\
\hline Corn & Zea mays & 3 \\
\hline \multicolumn{3}{|c|}{ Eudicots } \\
\hline Tomato & Solanum lycopersicum & 2 \\
\hline Potato & Solanum tuberosum & 2 \\
\hline Grapevine & Vitis vinifera & 1 \\
\hline Arabidopsis & Arabidopsis lyrata & 1 \\
\hline Arabidopsis & Arabidopsis thatiana & 1 \\
\hline Rapeseed & Brassica rapa & 2 \\
\hline Soybean & Glycine max & 2 \\
\hline Barrelclover & Medicago truncatula & 1 \\
\hline Peach & Prunus persica & 1 \\
\hline
\end{tabular}




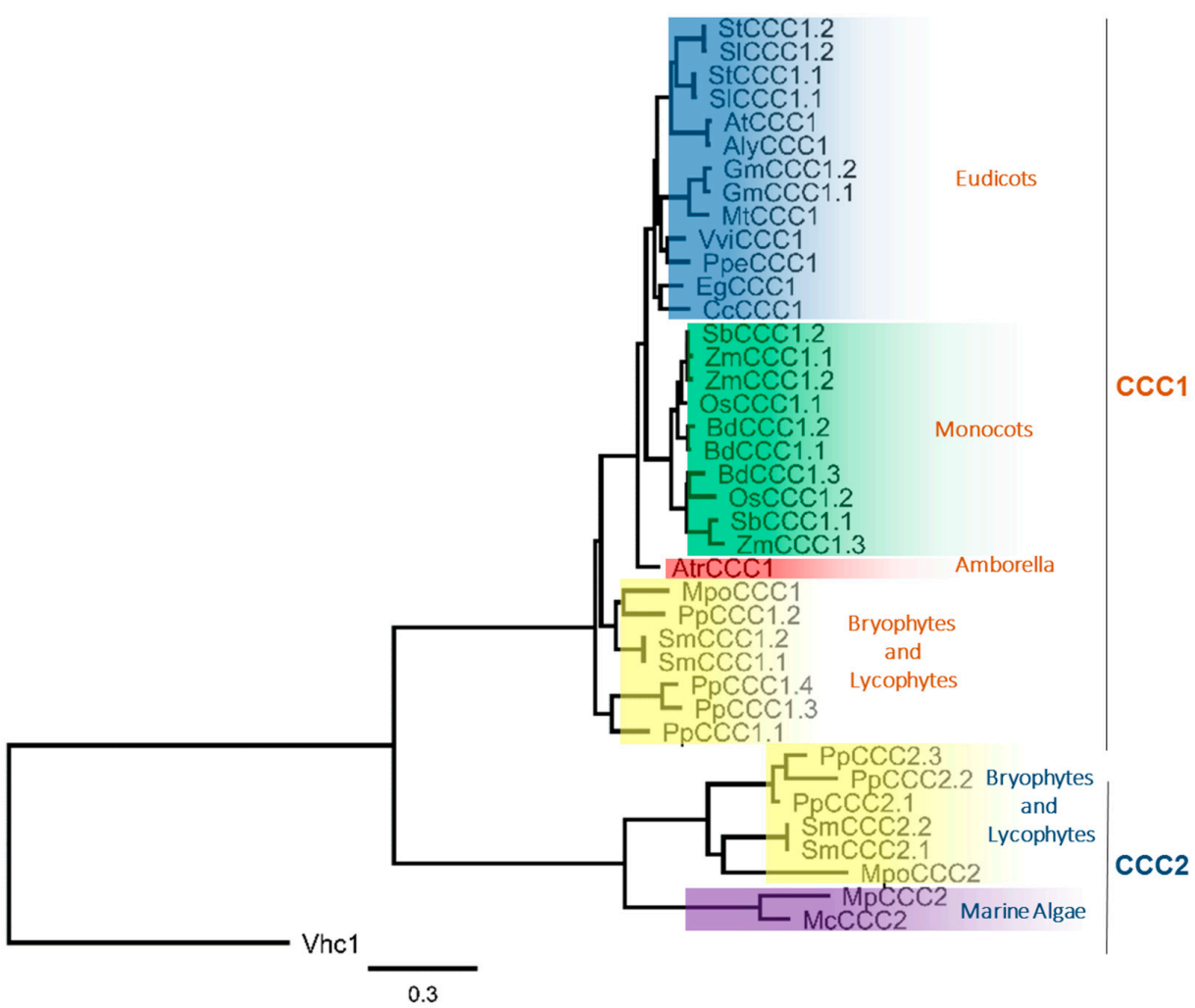

Figure 1. Phylogenetic relationship of the plant CCC family shows two distinct clades. Maximum likelihood tree rooted to yeast CCC "Vhc1". Generated using MUSCLE alignment, Gblocks curation followed by PhyML phylogeny (www.phylogeny.fr) [15]. See Table S1 for accession numbers.

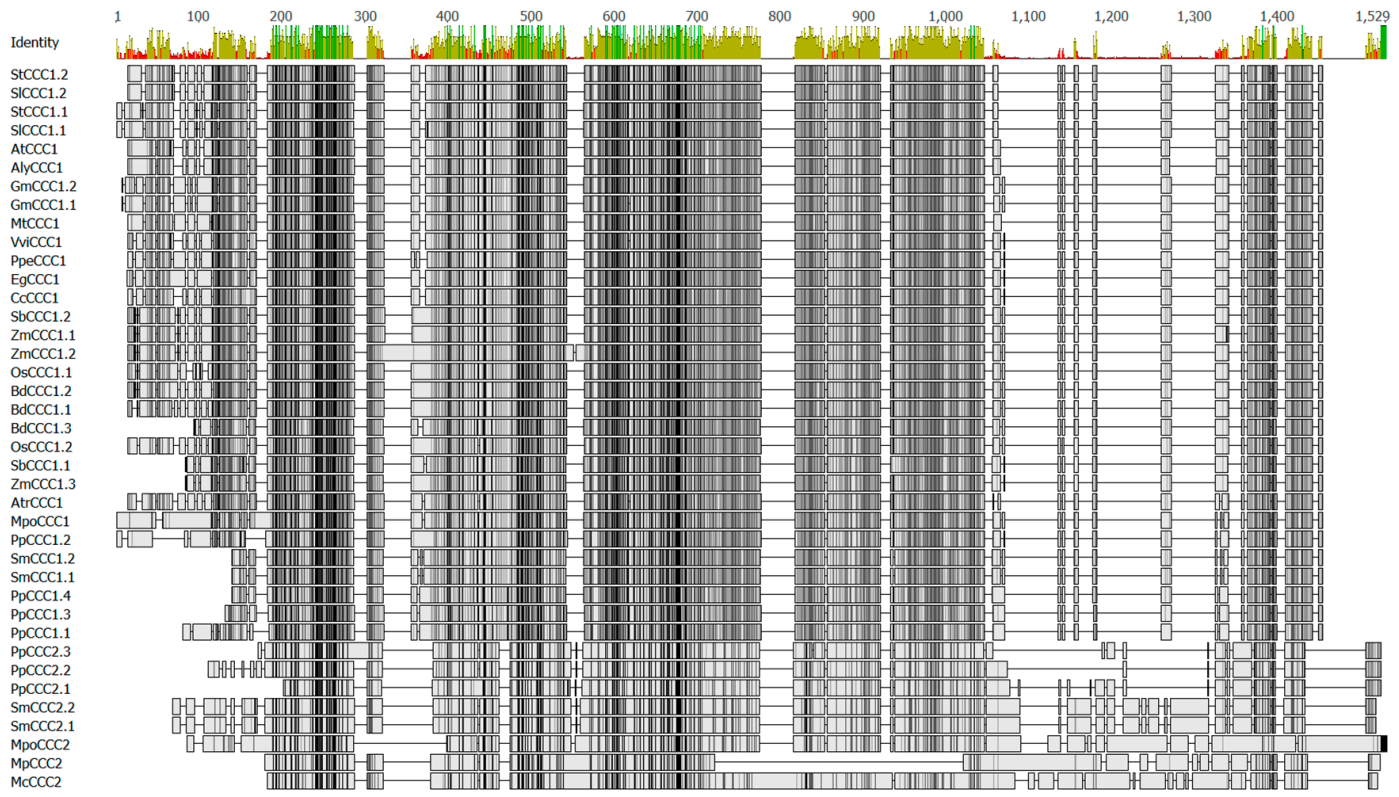

Figure 2. Amino acid sequence alignment of selected plant CCC proteins from Table 1 and Figure 1. Alignment was generated using Clustal Omega [16] and edited using Geneious R8 (Biomatters). Percent identity is shown above the alignment (green $100 \%$, brown $30 \%$ to $99 \%$, red $<30 \%$ ). Similarity shading is: black $100 \%$ similar; dark grey $80 \%$ to $99 \%$ similar; light grey $60 \%$ to $79 \%$ similar and white $<60 \%$ similar. For list of protein accession numbers, see Supplementary Table S1. For a percent identity matrix, see Table S2. 


\section{Putative Roles for CCC in Plant Growth and Development}

Phenotypes of $c c c$ loss-of-function mutants have been described in two plant species-Arabidopsis and rice. In both species, knockout mutants show an array of altered anatomical and physiological aspects and severely reduced fitness [3,6]. Directly connecting the function of the protein (i.e., ion transport) to the various phenotypic alterations in the knockout mutants is not straight forward. In general, plant $\mathrm{CCC} 1$ proteins seem to have a common function in different species, as constitutive ectopic expression of the grapevine VviCCC1 in the Arabidopsis $c c c 1$ mutant was able to complement the knockout phenotype [7]. Whether a monocot CCC1 family member, or a CCC2 family member, is also able to rescue the Arabidopsis $c c c 1$ mutant would be interesting to test. In both Arabidopsis and rice, loss of a known functional CCC1 leads to stunted shoot growth (Figure 3) and short roots $[3,6]$. Furthermore, rice $c c c$ roots are smaller in diameter and consist of smaller cells [6], while this has not yet been characterized in Arabidopsis. Arabidopsis ccc plants display a complete loss of shoot apical dominance, are heavily branched, and the emerging inflorescence stems frequently develop necrosis in the elongation zone [3]. This might indicate a role for $\mathrm{CCC} 1$ in rapidly elongating cells, for example for turgor establishment or regulating delivery of lipids and/or cell wall material to the plasma membrane. The loss of apical dominance might be connected to this frequent necrosis in the elongation zone, or possibly to a failure to establish an auxin gradient through a yet unknown mechanism. Disrupted auxin gradients are responsible for dwarf and bushy phenotypes in other Arabidopsis mutants such as echidna (ech) [17,18], myosin 2 (mya2) [19] and weak auxin response1 (wxr1) [20]. How mutation of an inorganic ion transporter in $c c c 1$ mutants confers such a phenotype is therefore unclear.
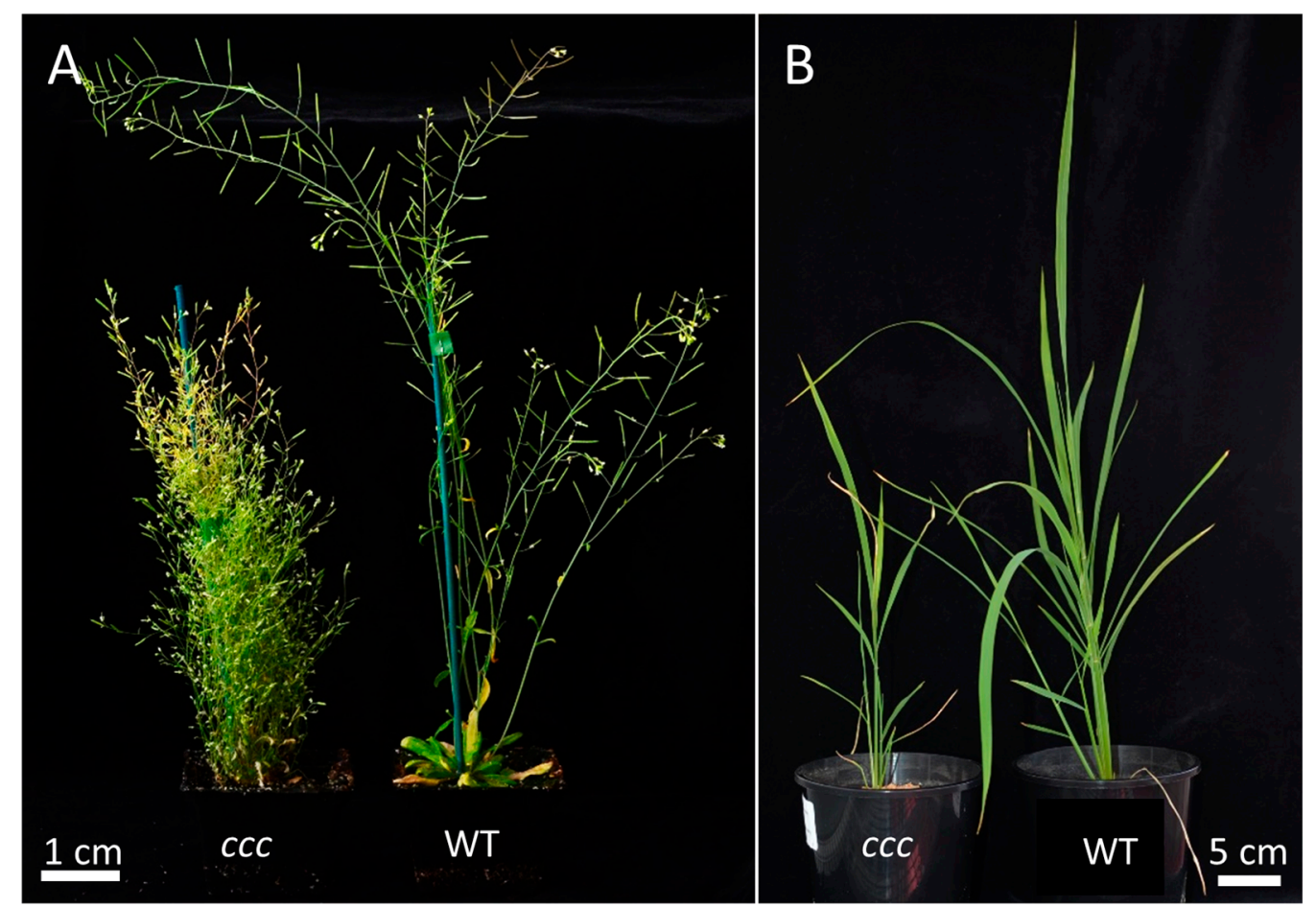

Figure 3. Phenotypes of mature Arabidopsis (A); and rice (44 days after sowing) (B) ccc1 knockout plants compared to their respective wildtypes. The Arabidopsis knockout displays a complete loss of apical dominance, dwarfed growth, shorter siliques and reduced seed set [3], while the rice $c c c$ displays dwarfed growth and a reduced leaf blade size [6].

The first analysis of $C C C 1$ gene expression patterns was performed in Arabidopsis using a 723 base pair $(\mathrm{bp})$ promoter: $\beta$-Glucuronidase (GUS) construct. These experiments indicated that $\mathrm{AtCCC} 1_{\text {pro }}$ drives GUS expression in specific tissues and cells types, with a high level of expression in the root 
tip, vasculature, stipules, hydathodes, stamen and pollen, while no expression was detected in the shoot meristem, in guard cells or epidermal cells [3]. This contrasts with the wide impact of the loss-of-function on the plant, and with the variety of phenotypic aspects observed in many different plant organs. Arabidopsis CCC1 was not present on the first generations of most microarray chips; however, some more recent studies using RNAseq in Arabidopsis show that AtCCC1 is expressed in root hairs and root epidermis [21], which demonstrates that AtCCC1 is expressed in other tissue types besides those detected by the GUS reporter system.

In grapevine, tissue specific expression analysis by semi-quantitative RT-PCR revealed that VviCCC1 is expressed in all tissue types tested, including flowers, berries, leaves and roots [7]. In rice, tissue specific expression analysis by quantitative real-time PCR (qPCR) revealed OsCCC1.1 expression in leaves and very high expression in the root tip [22]. Furthermore, OsCCC1.1-promoter (2.5 kb) driven expression of the OsCCC1.1 protein C-terminally tagged with GFP revealed additional expression in all root cell types [6]. In that study, antibodies raised against a short peptide (corresponding to residues 870 to 887 of OsCCC1.1), indicated protein presence in the root tip and in all leaf cells [6]. This is in agreement with qPCR studies of PtrCCC from trifoliate orange (Poncirus trifoliata) root tips [23]. Expression of AtCCC in stamens was found in an early study searching for genes essential for correct gametophytic function [24]. In that study, AtCCC1 was named HAP5 (for hapless), and the $c c c 1$ allele showed reduced transmission in both female and male gametophytes in the quartet 1 pollen mutant background [24]. AtCCC1 function is therefore important for pollen development, and for correct function or development of the embryo sac [24]. How exactly the ion transporter influences all these aspects remains unknown.

Some of the CCC proteins in mammals are associated with osmoregulation in organs such as kidneys, for example the human hNKCC2 [4]. A similar function (i.e., cellular osmoregulation) might also be possible in plants. Rice OsCCC1.1 is important for reaching optimal root osmolality (cell sap, xylem and phloem content not separated) [6], while Arabidopsis AtCCC1 and grapevine VviCCC1 might play a role in ion homeostasis, which might include adjustment to increased osmolality when salts are applied to the growth medium [3,7]. However, the complex phenotype of Arabidopsis knockout plants suggests that osmotic adjustment, if AtCCC1 plays a role here, is not the only cause. Interestingly, both AtCCC1 and VviCCC1 are localized to the Golgi and trans-Golgi network (TGN), and fluorescent fusion proteins are not readily detectible on the plasma membrane [7,25]. It is possible that CCC only localizes to the plasma membrane in specific cell types or under specific conditions, like for example the Arabidopsis iron transporter IRT1 [26], or that CCC is involved in processes in these organelles, such as vesicle formation or cargo selection. Conversely, rice OsCCC1.1 is possibly additionally localized on the plasma membrane [6].

\section{Influence of CCC Proteins on Plant Ion Homeostasis}

Chloride is a component of salt stress when plants are exposed to high salt concentrations [27], and an important plant macronutrient at lower salt concentrations [28]. $\mathrm{As} \mathrm{Cl}^{-}$is one of the known substrates of CCC proteins from both plants and animals, some studies have investigated CCC proteins to determine their role in $\mathrm{Cl}^{-}$homeostasis $[2,7,22]$. One study ectopically expressed $\operatorname{PtrCCC}$ from trifoliate orange in stably transformed Nicotiana nudicaulis using the constitutive CaMV35S promoter [23]. In that study, less $\mathrm{Cl}^{-}$was present in roots and shoots of transgenic lines under $\mathrm{KCl}$ stress compared to wild-type [23]. However, in a comparison of the closely related $\mathrm{Cl}^{-}$-including and $\mathrm{Cl}^{-}$-excluding Citrus spp. rootstocks (Cleopatra mandarin and Carrizo citrange, respectively), CcCCC was not found to be transcriptionally regulated by $\mathrm{Cl}^{-}$treatment. This was also the case when CCC expression was compared between Vitis spp. rootstocks with contrasting $\mathrm{Cl}^{-}$-exclusion capacities under control and mixed $\mathrm{Cl}^{-}$treatments by microarray hybridization [29] and qPCR [7]. The level of expression of PtrCCC in transgenic N. nudicaulis relative to the endogenous N. nudicaulis CCC was not determined [23], but presumably the transgenic tobacco lines would have expressed PtrCCC at a greater abundance than natively in P. trifoliata. The mechanism for reduced root and shoot 
$\mathrm{Cl}^{-}$in transgenic tobacco is unknown. In another study using Lotus as a reference, and assuming a stoichiometry of $1 \mathrm{~K}^{+}: 1 \mathrm{Na}^{+}: 2 \mathrm{Cl}^{-}$, it was concluded that transport would most likely be towards the xylem if the CCC transporter resided on the plasma membrane of root xylem parenchyma cells [30]. Hence, it is unlikely that CCC proteins contribute to the role of xylem parenchyma cells as gatekeepers for xylem retrieval of potentially toxic $\mathrm{Na}^{+}$and $\mathrm{Cl}^{-}$ions [31]. Conclusions that plant $\mathrm{CCC}$ proteins are responsible for salt tolerance must therefore be carefully considered. In Citrus, grapevine and probably in some other plant species, CCC genes are not transcriptionally regulated, but they might be regulated post-transcriptionally by phosphorylation. AtCCC has been identified as a putative mitogen activated protein kinase 6 (MPK6) phosphorylation target [32]. Phosphorylation and de-phosphorylation of animal NKCCs drastically changes the NKCC ion transport properties [33]. Further studies are required to investigate the regulation of plant CCCs.

\section{Water as a Putative Substrate of Plant CCC Proteins}

The concept that proteins in the plasma membrane of plant cells might simultaneously transport ions and water has existed for some time [34]. In the water-cotransport scenario, the net free energy change of water and ion cotransport could be thermodynamically favorable despite unfavorable thermodynamics for water movement by itself. Several studies in mammals have identified CCC proteins that have water and ion cotransporter activity. Using simultaneous swelling and tracer flux experiments in oocytes from the African clawed toad Xenopus laevis, mouse (Mus musculus) NKCC2 was shown to transport 460 water molecules for each turnover of the protein [35]. These observations have led to the suggestion that CCC proteins from vascular plants could have a similar function, and be responsible for ion-coupled water transport-providing a molecular mechanism for phenomena such as root pressure gradients and embolism repair in xylem vessels [36-39]. This is a possible scenario, especially since an Arabidopsis aquaporin (AtPIP2;1) was recently shown to permeate both water and sodium ions [40]. The energy consumption for night-time filling of root xylem vessels of barley via a water-ion cotransport mechanism under $12 \mathrm{~h}$ light/dark cycle, was calculated to be $0.0135 \%$ of the energy provided through photosynthesis [41]. In that study, it could not be excluded that water cotransport in plants contributes significantly to xylem filling during night-time transpiration [41]. However, at present, there is insufficient evidence to conclude that CCC proteins have a role in ion-coupled water movement.

Ion-coupled water transport into the root xylem is unlikely to be the exclusive role of CCC proteins in planta, because (as mentioned in Section 3) AtCCC1 promoter GUS expression and RNA-sequencing revealed expression in many tissues types, and not exclusive expression in the vasculature [3]. Furthermore, transcripts encoding OsCCC1.1, VviCCC1 and PtrCCC1 show variable expression patterns in many different root and shoot tissues $[6,7,22,23]$. Further experiments are indeed required to determine whether plant $\mathrm{CCC} 1$ and $\mathrm{CCC} 2$ proteins, like mouse NKCC2, are dual water ion cotransporters [39].

\section{Using Pharmacology to Gain Insight into Plant CCC Transport Function}

Loop diuretics are pharmaceutical compounds that are often used to treat hypertension in humans. The loop diuretics furosemide, thiazide and bumetanide achieve this function by acting as blockers of CCC proteins. These synthetic compounds function as competitive inhibitors at the $\mathrm{Cl}^{-}$binding site of the cotransporter. Furosemide preferentially inhibits KCCs, thiazides inhibit NCCs, while bumetanide inhibits NKCCs. In addition to its effect on mammalian CCC proteins of the NKCC class, bumetanide seems to have a direct pharmacological blockage effect on plant CCC proteins expressed in X. laevis oocytes [3]. However, the information gained about plant proteins in an animal expression system is limited, as animal cells are inherently sensitive to loop diuretics themselves (X. laevis oocytes express their own CCCs, described in Section 7.1). Thus, what can we infer from the application of these inhibitors to plant cells in vivo? 
Germination of tobacco pollen grains was weakly inhibited $(<50 \%)$ by furosemide and bumetanide treatment [42]. Since the effect of the inhibitors on germination was only achieved at very high concentration $(1 \mathrm{mM})$, it was concluded to most likely be nonspecific [42]. These results indicate that CCC proteins are inaccessible to the applied inhibitor or they might not be required for pollen germination. This is consistent with the phenotype of Arabidopsis ccc (hap5) pollen, which developed poorly but developed pollen were still able to germinate and fertilize the female gametophyte [24]. Hence, the in planta function of CCC in reproduction may predominately occur before pollen germination.

Bumetanide has been demonstrated to act as a plant defense elicitor. When applied at $100 \mu \mathrm{M}$ to suspension cells or roots of whole seedlings, bumetanide stimulated pathogen induced cell death, which enhanced the resistance to Pseudomonas syringae pv. Tomato [43]. It is tempting to speculate that this immune-priming of Arabidopsis to P. syringae arises through inactivation of CCC proteins by bumetanide. However, numerous other synthetic compounds, with no known CCC inhibitory activity, had similar immune priming effects on Arabidopsis [44-46]. Therefore, more research is required to uncover the mode of action of bumetanide in plant immunity.

CCC inhibitors, including bumetanide, also affect ion fluxes in root cells of whole plants. Arabidopsis root cells have been shown to have a fast acting, passive $\mathrm{Cl}^{-}$influx upon exposure to salt, followed by a slower $\mathrm{Cl}^{-}$influx phase most probably mediated by active or secondary active transport. In one study, salt-induced $\mathrm{Cl}^{-}$influx into cells of the root-hair-zone in Arabidopsis seedlings during the active uptake phase was inhibited by $100 \mu \mathrm{M}$ bumetanide to around $40 \%$ [47]. Compatible with this, $\mathrm{Na}^{+}$and $\mathrm{K}^{+}$efflux from isolated barley root stelar tissue (from three-day-old seedlings) was inhibited in the presence of $100 \mu \mathrm{M}$ bumetanide [48]. While this inhibition of influx and efflux could be due to blocking the $\mathrm{Na}^{+}-\mathrm{K}^{+}-\mathrm{Cl}^{-}$cotransport of the CCC at the plasma membrane, the localisation of AtCCC1-GFP to endomembranes in tobacco leaves and Arabidopsis protoplasts [7], as well as proteomic data $[49,50]$ would suggest a different mechanism. One alternative is that bumetanide blocks the CCC-mediated trafficking of other anion and cation channels to the plasma membrane, or the delivery of vesicles containing ions to the plasma membrane for extracellular release. This might explain why other anion channel blockers like 4, $4^{\prime}$-diisothiocyanatostilbene-2,2'-disulfonic acid (DIDS) had a much greater inhibitory effect on salt-induced root $\mathrm{Cl}^{-}$influx of Arabidopsis compared to bumetanide [47].

\section{Useful Expression Systems to Functionally Characterize Plant CCC Proteins}

Various heterologous expression systems have been used to functionally characterize mammalian CCC proteins, either alone or co-expressed with an interacting partner (e.g., protein kinases). Some of these expression systems have been applied to the study of plant CCC proteins.

\subsection{Xenopus laevis Oocytes}

Plant CCC proteins reach the plasma membrane when expressed in X. laevis oocytes [7]. This enables net ion fluxes through CCC to be directly measured. In oocytes expressing AtCCC1, the net uptake of radiotracers ${ }^{22} \mathrm{Na},{ }^{86} \mathrm{Rb}\left(\right.$ for $\mathrm{K}^{+}$) and ${ }^{36} \mathrm{Cl}$ was measured by scintillation counting, and results indicated that AtCCC1 mediates uptake of all three ions [3]. Similar results were found when this technique was applied to investigate the substrates of VviCCC1 [7]. Although these results are indicative of plant CCC proteins having an inorganic ion cotransporter function, a few complications of the X. laevis oocyte expression system for plant CCC proteins should be noted. Firstly, the activity of plant CCC proteins expressed in X. laevis oocytes is much lower compared to the activity of exogenously expressed mammalian CCCs in this system. Secondly, oocytes themselves harbor endogenous electroneutral KCC and NKCC proteins with quite high activities [51,52]. Additionally, the ${ }^{86} \mathrm{Rb}$-uptake activity of the endogenous bumetanide-sensitive NKCC of X. laevis oocytes is highly dependent on season, and animal housing and husbandry [53]. Thus, the radiotracer uptake activity of X. laevis oocytes expressing a plant CCC (relative to non-expressing controls) could show variations 
across batches, seasons or even laboratories. Silencing the endogenous X. laevis CCC cannot be considered a viable option because the cellular machinery required for RNA-induced gene silencing is not fully developed in X. laevis oocytes [54]. Thus, alternative mammalian expression systems may help to elucidate the functional properties of plant CCC proteins. A low K-resistant epithelial mutant cell line, derived from dog kidney, has previously been demonstrated to have little bumetanide-sensitive ${ }^{86} \mathrm{Rb},{ }^{22} \mathrm{Na}$, or ${ }^{36} \mathrm{Cl}$ uptake (<2\% of control) [55]. This cell line, known as Madine Derby canine kidney (MDCK) LK-C1, was successfully employed to study human hNKCC1 [56], and may provide an alternative to X. laevis oocytes and potentially be a promising tool for the study of plant CCC proteins.

\subsection{Yeast}

Yeast (Saccharomyces cerevisiae) is a useful expression system for characterizing plant ion transporters with cation selectivity [57], and has been used for such proteins as the High Affinity $\mathrm{K}^{+}$ Transporters (HKT) [58] and the inward rectifying $\mathrm{K}^{+}$channel KAT1 among other proteins. OsCCC1.1 complemented the $\mathrm{K}^{+}$uptake deficient $(\operatorname{trk} 1 \Delta \operatorname{trk} 2 \Delta)$ mutant CY162 [6], suggesting that OsCCC1.1 is capable of $\mathrm{K}^{+}$uptake in yeast. Similarly, when expressed in the mutant yeast strain G19, which

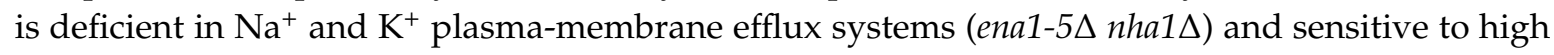
$\mathrm{Na}^{+}$concentrations, OsCCC1.1 exacerbated the phenotype [6], which suggests $\mathrm{Na}^{+}$uptake through OsCCC1.1. Interestingly, overexpression of hNKCC2 had the opposite effect of OsCCC1.1 on a

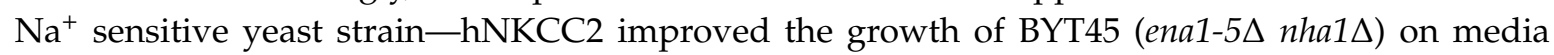
containing high $\mathrm{KCl}$ and $\mathrm{NaCl}$ concentrations [59]. This opposite effect cannot be explained yet, but might be due to different transport directions or different subcellular localizations of human and plant CCC proteins in yeast cells. The yeast CCC (named Vhc1) is localized to the yeast vacuolar membrane [60], while hNKCC2-GFP was found in the endoplasmic reticulum when expressed in yeast [59]. Determining the subcellular localization of plant CCC proteins in yeast may help to better interpret the results of this functional screen.

\section{Conclusions}

Despite numerous studies across a range of species, the role of CCC proteins in plants is not well defined. Plant and algal CCC proteins form two distinct phylogenetic clades, which are both more closely related to animal KCC than NKCCs. However, the function of proteins from the CCC2 clade, which is present in green algae and moss species, has not been examined yet. There are fewer CCC representatives in the genomes of Viridiplantae compared to other large multi-gene membrane protein families (except perhaps moss with seven CCC genes), and dicots contain the fewest number of CCC genes. Furthermore, knockout of plant genes from the CCC1 clade in angiosperms has drastic effects on growth and development. The mechanism by which functional disruption of CCC1 genes confers the multiple aspects of the knockout phenotypes is unclear. Future studies using mutagenized proteins and novel expression systems, to investigate protein domains of interest, are needed to identify structure-function relationships as well as the regulation of plant CCC proteins. Such experiments would allow the reconciliation of CCC membrane localization with protein function, and therefore more clearly establish the purpose of plant CCC.

Supplementary Materials: Supplementary Materials can be found at http:/ /www.mdpi.com/1422-0067/19/2/ $492 /$ s1.

Acknowledgments: We thank Steve Tyerman (University of Adelaide) for constructive comments on the manuscript. We thank Jian-Feng Ma (Okayama University) for kindly providing rice seeds. We are thankful to the Australian Research Council for funding this work through DE160100804 for Stefanie Wege and FT130100709 and CE140100008 to Matthew Gilliham.

Author Contributions: Sam W. Henderson, Stefanie Wege and Matthew Gilliham planned the manuscript; Sam W. Henderson and Stefanie Wege wrote the manuscript; and Matthew Gilliham edited and provided comment.

Conflicts of Interest: The authors declare no conflict of interest. 


\section{References}

1. Hartmann, A.-M.; Tesch, D.; Nothwang, H.G.; Bininda-Emonds, O.R.P. Evolution of the cation chloride cotransporter family: Ancient origins, gene losses, and subfunctionalization through duplication. Mol. Biol. Evol. 2014, 31, 434-447. [CrossRef] [PubMed]

2. Brumos, J.; Talon, M.; Bouhlal, R.Y.M.; Colmenero-Flores, J.M. $\mathrm{Cl}^{-}$homeostasis in includer and excluder Citrus rootstocks: Transport mechanisms and identification of candidate genes. Plant Cell Environ. 2010, 33, 2012-2027. [CrossRef] [PubMed]

3. Colmenero-Flores, J.M.; Martinez, G.; Gamba, G.; Vazquez, N.; Iglesias, D.J.; Brumos, J.; Talon, M. Identification and functional characterization of cation-chloride cotransporters in plants. Plant J. 2007, 50, 278-292. [CrossRef] [PubMed]

4. Simon, D.B.; Nelson-Williams, C.; Bia, M.J.; Ellison, D.; Karet, F.E.; Molina, A.M.; Vaara, I.; Iwata, F.; Cushner, H.M.; Koolen, M.; et al. Gitelman's variant of Bartter's syndrome, inherited hypokalaemic alkalosis, is caused by mutations in the thiazide-sensitive Na-Cl cotransporter. Nat. Genet. 1996, 12, 24-30. [CrossRef] [PubMed]

5. Kahle, K.T.; Staley, K.J.; Nahed, B.V.; Gamba, G.; Hebert, S.C.; Lifton, R.P.; Mount, D.B. Roles of the cation-chloride cotransporters in neurological disease. Nat. Clin. Pract. Neurol. 2008, 4, 490-503. [CrossRef] [PubMed]

6. Chen, Z.C.; Yamaji, N.; Kashino-Fujii, M.; Ma, J.F. A cation-chloride cotransporter gene is required for cell elongation and osmoregulation in rice. Plant Physiol. 2016, 171, 494-507. [CrossRef] [PubMed]

7. Henderson, S.W.; Wege, S.; Qiu, J.; Blackmore, D.H.; Walker, A.R.; Tyerman, S.D.; Walker, R.R.; Gilliham, M. Grapevine and Arabidopsis cation-chloride cotransporters localize to the Golgi and trans-Golgi network and indirectly influence long-distance ion transport and plant salt tolerance. Plant Physiol. 2015, 169, 2215-2229. [PubMed]

8. Bolser, D.; Staines, D.M.; Pritchard, E.; Kersey, P. Ensembl Plants: Integrating Tools for Visualizing, Mining, and Analyzing Plant Genomics Data. In Plant Bioinformatics. Methods in Molecular Biology; Edwards, D., Ed.; Humana Press: New York, NY, USA, 2016; Volume 1374.

9. Worden, A.Z.; Lee, J.H.; Mock, T.; Rouze, P.; Simmons, M.P.; Aerts, A.L.; Allen, A.E.; Cuvelier, M.L.; Derelle, E.; Everett, M.V.; et al. Green evolution and dynamic adaptations revealed by genomes of the marine picoeukaryotes Micromonas. Science 2009, 324, 268-272. [CrossRef] [PubMed]

10. Archibald, J.M. Green evolution, green revolution. Science 2009, 324, 191-192. [CrossRef] [PubMed]

11. Albalat, R.; Cañestro, C. Evolution by gene loss. Nat. Rev. Genet. 2016, 17, 379-391. [CrossRef] [PubMed]

12. Flagel, L.E.; Wendel, J.F. Gene duplication and evolutionary novelty in plants. New Phytol. 2009, 183, 557-564. [CrossRef] [PubMed]

13. International Wheat Genome Sequencing Consortium (IWGSC). A chromosome-based draft sequence of the hexaploid bread wheat (Triticum aestivum) genome. Science 2014, 345, 1251788.

14. Jarvis, D.E.; Ho, Y.S.; Lightfoot, D.J.; Schmöckel, S.M.; Li, B.; Borm, T.J.A.; Ohyanagi, H.; Mineta, K.; Michell, C.T.; Saber, N.; et al. The genome of Chenopodium quinoa. Nature 2017, 542, 307-312. [CrossRef] [PubMed]

15. Dereeper, A.; Guignon, V.; Blanc, G.; Audic, S.; Buffet, S.; Chevenet, F.; Dufayard, J.F.; Guindon, S.; Lefort, V.; Lescot, M.; et al. Phylogeny.fr: Robust phylogenetic analysis for the non-specialist. Nucleic Acids Res. 2008, 36, W465-W469. [CrossRef] [PubMed]

16. Sievers, F.; Higgins, D.G. Clustal Omega, accurate alignment of very large numbers of sequences. Methods Mol. Biol. 2014, 1079, 105-116. [PubMed]

17. Boutté, Y.; Jonsson, K.; McFarlane, H.E.; Johnson, E.; Gendre, D.; Swarup, R.; Friml, J.; Samuels, L.; Robert, S.; Bhalerao, R.P. ECHIDNA-mediated post-Golgi trafficking of auxin carriers for differential cell elongation. Proc. Natl. Acad. Sci. USA 2013, 110, 16259-16264. [CrossRef] [PubMed]

18. Fan, X.; Yang, C.; Klisch, D.; Ferguson, A.; Bhaellero, R.P.; Niu, X.; Wilson, Z.A. ECHIDNA protein impacts on male fertility in Arabidopsis by mediating trans-Golgi network secretory trafficking during anther and pollen development. Plant Physiol. 2014, 164, 1338-1349. [CrossRef] [PubMed]

19. Holweg, C.; Nick, P. Arabidopsis myosin XI mutant is defective in organelle movement and polar auxin transport. Proc. Natl. Acad. Sci. USA 2004, 101, 10488-10493. [CrossRef] [PubMed] 
20. Ge, L.; Peer, W.; Robert, S.; Swarup, R.; Ye, S.; Prigge, M.; Cohen, J.D.; Friml, J.; Murphy, A.; Tang, D.; et al. Arabidopsis ROOT UVB SENSITIVE2/WEAK AUXIN RESPONSE1 is required for polar auxin transport. Plant Cell 2010, 22, 1749-1761. [CrossRef] [PubMed]

21. Lan, P.; Li, W.; Lin, W.-D.; Santi, S.; Schmidt, W. Mapping gene activity of Arabidopsis root hairs. Genome Biol. 2013, 14, R67. [CrossRef] [PubMed]

22. Kong, X.-Q.; Gao, X.-H.; Sun, W.; An, J.; Zhao, Y.-X.; Zhang, H. Cloning and functional characterization of a cation-chloride cotransporter gene OsCCC1. Plant Mol. Biol. 2011, 75, 567-578. [CrossRef] [PubMed]

23. Wei, Q.; Ma, Q.; Ning, S.; Su, S.; Gu, Q. Molecular characterization and functional analysis of a cation-chloride cotransporter gene from trifoliate orange (Poncirus trifoliata L.). Trees 2017. [CrossRef]

24. Johnson, M.A.; von Besser, K.; Zhou, Q.; Smith, E.; Aux, G.; Patton, D.; Levin, J.Z.; Preuss, D. Arabidopsis hapless mutations define essential gametophytic functions. Genetics 2004, 168, 971-982. [CrossRef] [PubMed]

25. Nikolovski, N.; Rubtsov, D.; Segura, M.P.; Miles, G.P.; Stevens, T.J.; Dunkley, T.P.J.; Munro, S.; Lilley, K.S.; Dupree, P. Putative glycosyltransferases and other plant Golgi apparatus proteins are revealed by LOPIT proteomics. Plant Physiol. 2012, 160, 1037-1051. [CrossRef] [PubMed]

26. Barberon, M.; Zelazny, E.; Robert, S.; Conéjéro, G.; Curie, C.; Friml, J.; Vert, G. Monoubiquitin-dependent endocytosis of the IRON-REGULATED TRANSPORTER 1 (IRT1) transporter controls iron uptake in plants. Proc. Natl. Acad. Sci. USA 2011, 108, E450-E458. [CrossRef] [PubMed]

27. Li, B.; Tester, M.; Gilliham, M. Chloride on the move. Trends Plant Sci. 2017, 22, 236-248. [CrossRef] [PubMed]

28. Wege, S.; Gilliham, M.; Henderson, S.W. Chloride: Not simply a 'cheap osmoticum', but a beneficial plant macronutrient. J. Exp. Bot. 2017, 68, 3057-3069. [CrossRef] [PubMed]

29. Henderson, S.W.; Baumann, U.; Blackmore, D.H.; Walker, A.R.; Walker, R.R.; Gilliham, M. Shoot chloride exclusion and salt tolerance in grapevine is associated with differential ion transporter expression in roots. BMC Plant Biol. 2014, 14, 1-18. [CrossRef] [PubMed]

30. Teakle, N.L.; Tyerman, S.D. Mechanisms of $\mathrm{Cl}^{-}$transport contributing to salt tolerance. Plant Cell Environ. 2010, 33, 566-589. [CrossRef] [PubMed]

31. Henderson, S.W.; Gilliham, M. The "gatekeeper" concept: Cell-type specific molecular mechanisms of plant adaptation to abiotic stress. In Molecular Mechanisms in Plant Adaptation; Laitinen, R.A.E., Ed.; John Wiley \& Sons, Inc.: Hoboken, NJ, USA, 2015; pp. 83-115.

32. Sorensson, C.; Lenman, M.; Veide-Vilg, J.; Schopper, S.; Ljungdahl, T.; Grotli, M.; Tamas, M.J.; Peck, S.C.; Andreasson, E. Determination of primary sequence specificity of Arabidopsis MAPKs MPK3 and MPK6 leads to identification of new substrates. Biochem. J. 2012, 446, 271-278. [CrossRef] [PubMed]

33. Rinehart, J.; Vázquez, N.; Kahle, K.T.; Hodson, C.A.; Ring, A.M.; Gulcicek, E.E.; Louvi, A.; Bobadilla, N.A.; Gamba, G.; Lifton, R.P. WNK2 kinase is a novel regulator of essential neuronal cation-chloride cotransporters. J. Biol. Chem. 2011, 286, 30171-30180. [CrossRef] [PubMed]

34. Morillon, R.; Liénard, D.; Chrispeels, M.J.; Lassalles, J.-P. Rapid movements of plants organs require solute-water cotransporters or contractile proteins. Plant Physiol. 2001, 127, 720-723. [CrossRef] [PubMed]

35. Zeuthen, T.; MacAulay, N. Cotransport of water by $\mathrm{Na}^{+}-\mathrm{K}^{+}-2 \mathrm{Cl}^{-}$cotransporters expressed in Xenopus oocytes: NKCC1 versus NKCC2. J. Physiol. 2012, 590, 1139-1154. [CrossRef] [PubMed]

36. Wegner, L.H. Root pressure and beyond: Energetically uphill water transport into xylem vessels? J. Exp. Bot. 2014, 65, 381-393. [CrossRef] [PubMed]

37. Wegner, L.H. A thermodynamic analysis of the feasibility of water secretion into xylem vessels against a water potential gradient. Funct. Plant Biol. 2015, 42, 828-835. [CrossRef]

38. Wegner, L.H. Interplay of water and nutrient transport: A whole-plant perspective. In Progress in Botany; Lüttge, U., Beyschlag, W., Eds.; Springer International Publishing: Cham, Switzerland, 2015; Volume 76, pp. 109-141.

39. Wegner, L.H. Cotransport of water and solutes in plant membranes: The molecular basis, and physiological functions. AIMS Biophys. 2017, 4, 192-209. [CrossRef]

40. Byrt, C.S.; Zhao, M.; Kourghi, M.; Bose, J.; Henderson, S.W.; Qiu, J.; Gilliham, M.; Schultz, C.; Schwarz, M.; Ramesh, S.A.; et al. Non-selective cation channel activity of aquaporin AtPIP2;1 regulated by $\mathrm{Ca}^{2+}$ and $\mathrm{pH}$. Plant Cell Environ. 2017, 40, 802-815. [CrossRef] [PubMed]

41. Fricke, W. The significance of water co-transport for sustaining transpirational water flow in plants: A quantitative approach. J. Exp. Bot. 2015, 66, 731-739. [CrossRef] [PubMed] 
42. Matveyeva, N.P.; Andreyuk, D.S.; Yermakov, I.P. Transport of $\mathrm{Cl}^{-}$across the plasma membrane during pollen grain germination in tobacco. Biochemistry 2003, 68, 1247-1251. [CrossRef] [PubMed]

43. Noutoshi, Y.; Ikeda, M.; Shirasu, K. Diuretics prime plant immunity in Arabidopsis thaliana. PLoS ONE 2012, 7, e48443. [CrossRef] [PubMed]

44. Noutoshi, Y.; Ikeda, M.; Saito, T.; Osada, H.; Shirasu, K. Sulfonamides identified as plant immune-priming compounds in high-throughput chemical screening increase disease resistance in Arabidopsis thaliana. Front. Plant Sci. 2012, 3, 245. [CrossRef] [PubMed]

45. Noutoshi, Y.; Jikumaru, Y.; Kamiya, Y.; Shirasu, K. ImprimatinC1, a novel plant immune-priming compound, functions as a partial agonist of salicylic acid. Sci. Rep. 2012, 2, 705.

46. Noutoshi, Y.; Okazaki, M.; Kida, T.; Nishina, Y.; Morishita, Y.; Ogawa, T.; Suzuki, H.; Shibata, D.; Jikumaru, Y.; Hanada, A.; et al. Novel plant immune-priming compounds identified via high-throughput chemical screening target salicylic acid glucosyltransferases in Arabidopsis. Plant Cell 2012, 24, 3795-3804. [CrossRef] [PubMed]

47. Saleh, L.; Plieth, C. A9C sensitive $\mathrm{Cl}^{-}$-accumulation in A. thaliana root cells during salt stress is controlled by internal and external calcium. Plant Signal. Behav. 2013, 8, e24259. [CrossRef] [PubMed]

48. Zhu, M.; Zhou, M.; Shabala, L.; Shabala, S. Physiological and molecular mechanisms mediating xylem $\mathrm{Na}^{+}$loading in barley in the context of salinity stress tolerance. Plant Cell Environ. 2017, 40, 1009-1020. [CrossRef] [PubMed]

49. Drakakaki, G.; van de Ven, W.; Pan, S.; Miao, Y.; Wang, J.; Keinath, N.F.; Weatherly, B.; Jiang, L.; Schumacher, K.; Hicks, G.; et al. Isolation and proteomic analysis of the SYP61 compartment reveal its role in exocytic trafficking in Arabidopsis. Cell Res. 2012, 22, 413-424. [CrossRef] [PubMed]

50. Groen, A.J.; Sancho-Andrés, G.; Breckels, L.M.; Gatto, L.; Aniento, F.; Lilley, K.S. Identification of trans-Golgi network proteins in Arabidopsis thaliana root tissue. J. Proteome Res. 2013, 13, 763-776. [CrossRef] [PubMed]

51. Mercado, A.; de los Heros, P.; Vázquez, N.; Meade, P.; Mount, D.B.; Gamba, G. Functional and molecular characterization of the K-Cl cotransporter of Xenopus laevis oocytes. Am. J. Physiol. Cell Physiol. 2001, 281, C670-C680. [CrossRef] [PubMed]

52. Suvitayavat, W.; Palfrey, H.C.; Haas, M.; Dunham, P.B.; Kalmar, F.; Rao, M.C. Characterization of the endogenous $\mathrm{Na}^{+}-\mathrm{K}^{+}-2 \mathrm{Cl}^{-}$cotransporter in Xenopus oocytes. Am. J. Physiol. 1994, 266, C284-C292. [CrossRef] [PubMed]

53. Delpire, E.; Gagnon, K.B.; Ledford, J.J.; Wallace, J.M. Housing and husbandry of Xenopus laevis affect the quality of oocytes for heterologous expression studies. J. Am. Assoc. Lab. Anim. Sci. 2011, 50, 46-53. [PubMed]

54. Lund, E.; Sheets, M.D.; Imboden, S.B.; Dahlberg, J.E. Limiting Ago protein restricts RNAi and microRNA biogenesis during early development in Xenopus laevis. Genes Dev. 2011, 25, 1121-1131. [CrossRef] [PubMed]

55. Giesen-Crouse, E.M.; McRoberts, J.A. Coordinate expression of piretanide receptors and $\mathrm{Na}^{+}, \mathrm{K}^{+}, \mathrm{Cl}^{-}$cotransport activity in Madin-Darby canine kidney cell mutants. J. Biol. Chem. 1987, 262, 17393-17397. [PubMed]

56. Payne, J.A.; Ferrell, C.; Chung, C.Y. Endogenous and exogenous Na-K-Cl cotransporter expression in a low K-resistant mutant MDCK cell line. Am. J. Physiol. Cell Physiol. 2001, 280, C1607-C1615. [CrossRef] [PubMed]

57. Rodríguez, A.; Benito, B.; Cagnac, O. Using heterologous expression systems to characterize potassium and sodium transport activities. In Plant Salt Tolerance: Methods and Protocols; Shabala, S., Cuin, T.A., Eds.; Humana Press: Totowa, NJ, USA, 2012; pp. 371-386.

58. Henderson, S.W.; Dunlevy, J.D.; Wu, Y.; Blackmore, D.H.; Walker, R.R.; Edwards, E.J.; Gilliham, M.; Walker, A.R. Functional differences in transport properties of natural HKT1;1 variants influence shoot $\mathrm{Na}^{+}$exclusion in grapevine rootstocks. New Phytol. 2018, 217, 1113-1127. [CrossRef] [PubMed]

59. Petrezselyova, S.; Dominguez, A.; Herynkova, P.; Macias, J.F.; Sychrova, H. Human NKCC2 cation-Clco-transporter complements lack of Vhc1 transporter in yeast vacuolar membranes. Yeast 2013, 30, 395-402. [CrossRef] [PubMed]

60. Petrezselyova, S.; Kinclova-Zimmermannova, O.; Sychrova, H. Vhc1, a novel transporter belonging to the family of electroneutral cation- $\mathrm{Cl}^{-}$cotransporters, participates in the regulation of cation content and morphology of Saccharomyces cerevisiae vacuoles. Biochim. Biophys. Acta Biomembr. 2013, 1828, 623-631. [CrossRef] [PubMed]

(C) 2018 by the authors. Licensee MDPI, Basel, Switzerland. This article is an open access article distributed under the terms and conditions of the Creative Commons Attribution (CC BY) license (http://creativecommons.org/licenses/by/4.0/). 